\title{
Undiversifiable Returns in a CAPM Economy
}

Braila, Peghe; Wampach, Claude

Publication date:

2001

Document version

Early version, also known as pre-print

Citation for published version (APA):

Braila, P., \& Wampach, C. (2001). Undiversifiable Returns in a CAPM Economy. Department of Economics, University of Copenhagen. 


\title{
DISCUSSION PAPERS Department of Economics University of Copenhagen
}

\section{1-08}

Undiversifiable Returns in a CAPM Economy

\author{
Peghe Braila \\ Claude Wampach
}

Studiestræde 6, DK-1455 Copenhagen K., Denmark

Tel. +45 35323082 - Fax +45 35323000

http://www.econ.ku.dk 


\title{
Undiversifiable Returns in a CAPM Economy*
}

\author{
Peghe Braila $^{\dagger} \quad$ Claude Wampach
}

4 July 2001

\begin{abstract}
The effects of endogenous undiversifiable investment and market structure changes on security pricing are analyzed within the GEICAPM (General Equilibrium with Incomplete Markets Capital Asset Pricing Model). Both the mutual fund and security market line theorems are extended conditional to a redefinition of the market portfolio. Relative prices of securities are still determined by covariances with the aggregate endowment but they fail to preserve the "standard" invariance result of the CAPM with quadratic utilities. Asset prices may change in response to financial innovation.
\end{abstract}

Keywords: General Equilibrium with Incomplete Markets, Portfolio Choice, Transfer Technology, Capital Asset Pricing Model.

J.E.L Classification numbers: D50 (General Equilibrium), D52 (Incomplete Markets), G11 (Porfolio Choice), G12 (Asset Pricing).

\footnotetext{
${ }^{*}$ We thank Birgit Grodal, Chiaki Hara, Jean Jacques Herings and Heracles Polemarchakis for essential feedback at a number of stages of our research. Useful comments were given by seminar audiences at the Institute of Economics, University of Copenhagen and Department of Economics at the University of Lund.

†Institute of Economics, University of Copenhagen, Studiestraede 6, 1455 CopenhagenK. Denmark. Phone: +45 355230 27. E-mail: Peghe.Braila@econ.ku.dk

*Fixed Income Management, Banque Generale du Luxembourg, J.F. Kennedy Avenue 50, L-2951, Luxembourg. Phone: + 352424223 205. E-mail: Wampach.Claude@bgl.lu
} 


\section{Introduction}

Asset pricing theories share a common feature: Investors reduce risk by diversifying their portfolio in the financial markets as those are described by the range of traded financial assets. Risk premia are explained as compensations for assuming a risk that the investor alone cannot diversify. The Capital Asset Pricing Model (CAPM) is probably the most familiar asset pricing theory in which both portfolio and equilibrium aspects coexist. Built around the means and covariances of security payoffs, it has its roots in Markowitz's (1959) description of mean-variance portfolio selection problem. The CAPM uses a time series regression to measure a coefficient, called "the beta coefficient", which quantifies an asset's or portfolio's tendency to move with the market as a whole. "The market as a whole" is a macroeconomic variable and it is modeled as the aggregate endowment. The CAPM predicts that the asset's excess return should be proportional to beta which is measured by the covariance of the asset returns with the aggregate endowment. In the traditional derivation, the aggregate endowment is assumed to be diversifiable, since agents' endowments are spanned by the assets, but no assumption regarding the market structure is made. Indeed, Geanakoplos and Shubik (1990) have extended the model in the general equilibrium with incomplete markets context (GEI), proving that there is a single beta linear relationship between expected return and risk. This linear relationship is called "the security market line" property of asset prices and identifies with the regression equation mentioned above. The security market line results from the "two fund separation" equilibrium property ( or "mutual fund theorem") which states that agents are satisfied by holding two funds, only, the "riskless bond" and the "market portfolio". Moreover, consistent with the standard notion of risk, the security market line represents a positive relationship: "the riskier the assets, the higher the expected returns". Mayers (1972), Breeden (1979), and Grossman and Shiller (1982) have extended the CAPM to the case of non traded endowments and they establish a single beta linear relationship working in a complete markets framework. However, they have not shown if the relationship remains positive. Oh (1996) considers a general equilibrium with incomplete asset markets and shows that nontraded endowments can be allowed in the CAPM without sacrificing its powerful conclusions. In the CAPM with quadratic utilities, he shows that changes in the market structure do not affect the relative prices of existing assets and when agents have the same discount rate asset prices do not 
change at all. In his work completing the market is pareto improving since equilibrium allocations do change when prices do not.

In this paper we want to explore the CAPM in the general case where endowments are not spanned by the existing assets and they are endogenous (the realization of future income depends on past optimizing decisions). We adopt the GEI-CAPM with quadratic utilities and we introduce a productive investment decision from the part of the individuals. The returns on this investment are assumed not diversifiable by the existing assets and they affect present and future income (initial endowments). Sometimes, we refer to these activities as transfers of endowments. This specification loosens the assumption of fixed exogenous income usually made and, tries to take into account investment decisions that are not priced in a competitive setup but, nevertheless taken simultaneously with others involved in competitive trade. Examples such as small firms, individual entrepreneurships, and family businesses may advocate in favor of our model. Such productive entities are not listed in the stock market so their output is not making part of the market portfolio as defined in the traditional CAPM; this makes the return on these investments nontraded. The choice to represent their returns in a state space reflects the risk that is involved and the assumption that investment decisions are taken simultaneously with financial decisions (trading in the financial markets) seems quite realistic nowadays; this makes initial endowments endogenous. We address the validity of the two basic prescriptions of the CAPM, the mutual fund theorem and the security market line, when transfers of endowments are allowed. We show that exact portfolio separation fails and following the lead of Oh (1996) that prove that conditional on a redefinition of the market portfolio, a generalized mutual fund which asserts that the projection of optimal date-two consumption streams into the span of existing assets satisfies a separation property ${ }^{1}$. As mentioned already, the mutual fund theorem has an immediate corollary in terms of restrictions it imposes on expected asset payoffs, hence, we derive a generalized security market line, as well.

Finally, we investigate the rigidity of the asset prices in the GEI-CAPM with quadratic utilities, with respect to modifications in the structure of the financial market. Oh's result of invariance of asset prices is not carried out in our model. In the CAPM with quadratic utilities and endogenous endowments relative prices of the existing assets do change since the aggregate

\footnotetext{
${ }^{1}$ Projection into the span of assets defines a means to price non marketed portfolios.
} 
endowment depends on the market structure. When the market structure changes, each agents budget set is usually affected by two factors, an income effect due to the asset price change and a spanning constraint. When the span increases there is an income effect resulting from two factors the asset price change and the initial endowment change. Equilibrium prices and allocations change making the complete markets paradigm unstable in the sense that introducing a new asset does not necessarily makes noone worse off.

The paper is structured as follows. Section 2 describes a simple finance economy with undiversifiable investment and it builts a mean variance model for which it proves a generalized funds separation and a security market line. It shows how the already existing results fall into the generalized theorem as special cases. Section 3 presents the CAPM with quadratic utilities and highlights the effects of financial innovation on asset prices. It also provides an illustration by using the assumption of linear quadratic preferences. Section 4 gives a numerical example that showcase the financial innovation result. The paper concludes with a summary of the results and suggestions for future research.

\section{Undiversifiable Investment in the CAPM}

We study an extension of the finance version of the GEI-model that describes an economy over two periods of time, $t=0,1$, with uncertainty over the state of nature resolving in period $t=1$. A thorough description of the financial GEI-model can be found in Magill and Quinzii (1996); we extend the two periods finance model by endowing each agent with a stochastic productive process, called hereafter agent i's transfer technology of income. After laying aside an amount for consumption at date-0, agents may invest the remainder of their wealth in financial securities and in production, both investment decisions yielding a profile of income across the states at date- 1 . We adopt a special variation of the finance GEI model assuming mean-variance preferences for the agents which places us in a CAPM framework with nonmarketed but endogenous endowments. First, we describe our model and introduce the necessary notation. Second, we summarize the GEI-CAPM literature in a model that can be seen as a special case of our model, present the relevant results in order to obtain some insight for our findings. 


\subsection{The model}

There are $S+1$ states in the economy; at time $t=0$ the economy is in state 0 , one state of nature $s$ out of $S$ possible states realize. In each state $s=0, \ldots, S$, there is a single perishable consumption good.

There are $I$ agents, indexed by $i=1, \ldots, I$, that participate in the economy. Agent $i$ is characterized by a first period initial endowment $\omega_{0}^{i}$, preferences over consumption bundles and the agent specific stochastic income transfer technology $\widetilde{\lambda}^{i}($.$) .$

\section{Initial endowment vector $\omega_{0} \in \mathbb{R}_{+}^{I}$}

Preferences over consumption bundles (income streams available for consumption) $x^{i}=\left(x_{0}^{i}, x_{\mathbf{1}}^{i}\right) \in \mathbb{R}^{S+1}$ and $x_{\mathbf{1}}^{i}=\left(x_{1}^{i}, \ldots, x_{S}^{i}\right) \in \mathbb{R}^{S}$. We assume that all agents have VNM-additively separable utility functions across date events $\left(u^{i} \longleftrightarrow\left(v_{0}^{i}, v_{1}^{i}\right)\right), u^{i}: \mathbb{R}^{S+1} \longrightarrow \mathbb{R}, u^{i}$ satisfies strict quasi concavity, there exist probabilities $\rho_{1}, \ldots, \rho_{S}>0, \sum_{s=1}^{S} \rho_{s}=1$, for all $i$ the same (objective probabilities)

We want preferences to depend on the mean and the variance of consumption

$$
u^{i}\left(x^{i}\right)=v^{i}\left(x_{0}^{i}, E\left(x^{i}\right), \operatorname{var}\left(x^{i}\right)\right)
$$

with $v^{i}$ strictly increasing in $x_{0}^{i}$ and in expected consumption and strictly decreasing in the variance of consumption. This places us in a Mean-Variance (MV) analysis framework, which implies that agents judge income streams solely by their average properties summarized in their means and variances. Such agents prefer higher expected (mean) income and less income variation (variance).

Stochastic income transfer technology $\tilde{\lambda}^{i}()=.\bar{\omega}_{s}^{i}:\left[0, \omega_{0}^{i}\right] \longrightarrow$ $[1,+\infty), s=0,1, \ldots, S$ is assumed to be a strictly increasing, concave and continuously differentiable function of the input $l^{i}$,measured in units of the single good, on $\left(0, \omega_{0}^{i}\right)$.

Operating his individual transfer technology agent $i$ obtains the vector of the after transfer endowment or endogenous endowments vector denoted by $\bar{\omega}^{i}=\left(\bar{\omega}_{0}^{i}, \bar{\omega}_{1}^{i}\right) \in \mathbb{R}_{+}^{S+1}$. The aggregate after transfer endowment is denoted $\bar{w}=\left(\bar{w}_{0}, \bar{w}_{1}\right) \in \mathbb{R}^{S+1}$. 
At date- 0 agents trade in $J$ real securities of which payoffs are brought together in the $S \times J$ matrix

$$
V=\left[\begin{array}{ccc}
1 & \ldots & V_{1}^{J} \\
\ldots & \ddots & \ldots \\
1 & \ldots & V_{S}^{J}
\end{array}\right],
$$

with the $j$ column of the payoff matrix representing the income stream generated by security $j=1, \ldots, J$ in each state $s=1, \ldots, S$. The matrix $V$ has full column $\operatorname{rank} \operatorname{rank}(V)=J, J<S$; this assumption excludes redundant assets from the financial structure and places us in the GEI setup. The first column, $j=1$, of $V$ is the column vector $\mathbf{1}=(1, \ldots, 1) \in \mathbb{R}^{S}$, implying the presence of the riskless security (riskless bond) in the span of the assets. At this point we can formalize our economy by the following definition.

Definition 1 The economy. A GEI-CAPM economy with endogenous endowments $\overline{\mathcal{E}}\left(u, \omega_{0}, V, \widetilde{\lambda}\right)$ is an exchange economy consisting of I agents with characteristics $(u, \omega)=\left(u^{1}, \ldots, u^{I}, \omega^{1}, \ldots, \omega^{I}\right)$, who, additionally to trading $J$ securities with period-1 payoffs given by the matrix $V$, they transfer into period-1, period-0 income through the stochastic technologies $\widetilde{\lambda}_{i}, i=1, \ldots, I{ }^{2}$

Let $q=\left(q_{1}, \ldots, q_{J}\right) \in \mathbb{R}^{J}$ denote the vector of prices, expressed in units of the single good for each of the $J$ securities. For the riskless bond, we have $q_{1}=1 /(1+r)$ with $r$ the riskless rate of interest. All securities are in zero net supply ${ }^{3}$. By $z^{i}=\left(z_{1}^{i}, \ldots, z_{J}^{i}\right) \in \mathbb{R}^{J}$, we denote the $i^{\text {th }}$ agent's portfolio; $z_{j}^{i}$ gives the number of units security $j$ purchased $\left(z_{j}^{i}>0\right)$ or sold $\left(z_{j}^{i}<0\right)$ by agent $i$; this is the unlimited short sales assumption.

The budget set of agent $i$ is given by

$$
\mathbb{B}\left(q, \omega^{i}, V, \tilde{\lambda}^{i}\right)=\left\{\begin{array}{c}
x_{0}^{i}-\omega_{0}^{i}=l^{i}+q z^{i}, x_{0}^{i} \in \mathbb{R}_{+}, 0 \leq l^{i} \leq \omega_{0}^{i}, z^{i} \in \mathbb{R}^{J} \\
x_{\mathbf{1}}^{i}=\bar{\omega}_{\mathbf{1}}^{i}+V z^{i}, x_{\mathbf{1}}^{i} \in \mathbb{R}_{+}^{S}
\end{array}\right\}
$$

\footnotetext{
${ }^{2}$ This definition is a generalized definition of a GEI-CAPM economy, in the sense that it may include the pure exchange case, if we will assume that $\tilde{\lambda}^{i}(0)=\omega_{s}^{i}, s=1, \ldots, S$, where $\omega^{i} \in \mathbb{R}^{S}$, vector of exogenously given initial endowments.

${ }^{3}$ As shown in Magill and Quinzii (1996), a simple change of variable permits equity contracts to be modelled as securities in zero net supply, as well.
} 
Agent $i$ decides on a triple of actions $\left(x^{i}, l^{i}, z^{i}\right)$, consisting of an $(S+$ 1) dimensional vector of consumption, a portfolio and an amount of input, measured in units of the single consumption good, in his transfer technology. Agents maximize utility on their budget sets and in a competitive equilibrium with endogenous endowments it should be that, at least one of them uses a positive fraction of his initial endowment as an input into his transfer technology. More formally, the concept of a perfectly competitive equilibrium for the $I$ agents who simultaneously trade in $J$ assets and use their transfer technology, endogenizing in this way, their initial endowments, is defined as follows ${ }^{4}$.

Definition 2 Equilibrium. An equilibrium for the GEI-CAPM economy with endogenous endowments $\overline{\mathcal{E}}\left(u, \omega_{0}, V, \widetilde{\lambda}\right)$ is a pair consisting of actions and prices $\left(\left(x^{i}, l^{i}, z^{i}\right), \bar{q}\right) \in \mathbb{R}_{+}^{(S+1) I} \times \mathbb{R}^{I} \times \mathbb{R}^{J I} \times \mathbb{R}^{J}$ such that

(i) $\left(\bar{x}^{i} ; \bar{l}^{i}, \bar{z}^{i}\right) \in \arg \max \left\{u^{i}\left(x^{i}\right) \mid\left(x^{i} ; l^{i}, z^{i}\right) \in \mathbb{B}\left(q, \omega^{i}, V, \widetilde{\lambda}^{i}\right)\right\}, i=1, \ldots, I$,

(ii) $\sum_{i=1}^{I} \bar{z}^{i}=0$,

(iii) $0<l^{i}<\omega_{0}^{i}$ some $i=1, \ldots, I$.

\subsection{The Generalized GEI-CAPM}

In this section we generalize, allowing for endogenous endowments, the findings in the GEI literature related to the CAPM, in a finite state space. The presentation follows Magill and Quinzii (1996).

We add to the above formalization the following definitions. For a random variable $x \in \mathbb{R}^{S}$, we define its expectation as $E(x)=\sum_{s=1}^{S} \rho_{s} x_{s}, s=1, \ldots, S$, its covariance with a random vector $y \in \mathbb{R}^{S}$ as $\operatorname{cov}(x, y)=E x y-E x E y=$ $\sum_{s=1}^{S} \rho_{s} x_{s} y_{s}-E x E y$ and its variance as $\operatorname{var}(x)=\operatorname{cov}(x, x)=\sum_{s=1}^{S} \rho_{s} x_{s}^{2}-$ $(E x)^{2}$. We also denote by $x_{V}$ the $\rho$-orthogonal projection ${ }^{5}$ of a vector $x \in \mathbb{R}^{S}$ onto the marketed subspace $\langle V\rangle$. Finally, we define the $\rho$-inner product of two vectors as $x \cdot{ }_{\rho} y=\sum_{s=1}^{S} \rho_{s} x_{s} y_{s}$ for $x, y \in \mathbb{R}^{S}$.

\footnotetext{
${ }^{4} \mathrm{~A}$ proof of the existence of equilibrium is beyond of the scope of this paper.

${ }^{5}$ The $\rho$-orthogonal projection of $x \in \mathbb{R}^{S}$, onto a subspace of $\mathbb{R}^{J} \subset \mathbb{R}^{S}$, is the vector $x^{*} \in \mathbb{R}^{S}$ which best approximates (lies closest to) $x . x^{*}$ is called also the linear (least squares) regression of $x$ on $\mathbb{R}^{J}$.
} 
Asset prices in the GEI model are characterized by no arbitrage, agent's optimization and market clearing. Competitive equilibrium prices are non arbitrage prices and thus can be written as $\bar{q}=\pi \cdot{ }_{\rho} V q \in \mathbb{R}^{J}$, where $\pi \in \mathbb{R}_{++}^{S}$ is a vector of strictly positive state prices (implicit prices of revenue across states). Since the securities market is incomplete, state prices consistent with the above linear pricing rule are not unique. The $\rho$-orthogonal projection of the vector $\pi$ onto the marketed subspace however is unique, call it pricing vector or ideal security, and denote it as $\bar{\pi}_{V} \in\langle V\rangle$. Then for all assets $j=1, \ldots, J$ we have $\bar{q}_{j}=\pi_{V} \cdot{ }_{\rho} V^{j}$. Using the definitions of variance and covariance, we can write

$$
\bar{q}_{j}=E\left(\pi_{V}\right) E\left(V^{j}\right)+\operatorname{cov}\left(\pi_{V}, V^{j}\right)
$$

The return of a portfolio $z \in \mathbb{R}^{J}$ is defined as the fraction of its value $V z$ over its cost $\bar{q} z$ and denoted by $R_{z}=\frac{V z}{\bar{q} z}$, (with $\bar{q} z \neq 0$ ). The return on the riskless bond, therefore is $\bar{R}=1+\bar{r}=1 / \bar{q}_{1}$; it also defines the riskless interest rate $\bar{r}$. Equation (2), then, can be written as

$$
\bar{q}_{j}=\frac{E\left(V^{j}\right)}{\bar{R}}+\operatorname{cov}\left(\pi_{V}^{*}, V^{j}\right)
$$

The portfolio that generates the ideal security is called the pricing portfolio and it is the unique portfolio $z^{*}$ which solves $V z^{*}=\pi_{V}^{*}$.

It holds

$$
\bar{q} z^{*}=\pi_{V}^{*} \cdot \rho V z^{*}=\pi_{V}^{*} \cdot \rho \pi_{V}^{*}>0,
$$

since $E\left(\pi_{V}^{*}\right)=\bar{q}_{1}>0$.

We can rewrite the equation (2) as

$$
E\left(R_{z}\right)-\bar{R}=\frac{\operatorname{cov}\left(R_{z}-R_{z^{*}}\right)}{\operatorname{var}\left(R_{z^{*}}\right)}\left(E\left(R_{z^{*}}\right)-\bar{R}\right),
$$

where $R_{z^{*}}=\frac{V z^{*}}{q z^{*}}=\frac{\pi_{V}^{*}}{\pi_{V}^{*} \cdot \rho \pi_{V}^{*}}$ the return of the pricing portfolio.

Equation (3) has been derived by only assuming no arbitrage and, for it to become a useful pricing formula we need further information on the ideal security (pricing vector) $\pi_{V}^{*}$. 
It is well known that under the assumption that at least one agent $i / s$ utility functions is differentiable and that in an equilibrium with an interior solution, $\pi_{V}^{*}$ can be characterized as the $\rho$-orthogonal projection of the vector of the marginal rates of substitution between date events devided by the corresponding probabilities, onto the marketed subspace $\langle V\rangle$, i.e.,

$$
\pi_{V}^{*}=\left(\frac{\partial_{x_{1}^{i}} u\left(\bar{x}^{i}\right) / \rho_{1}}{\partial_{x_{0}^{i}} u\left(\bar{x}^{i}\right)}, \ldots, \frac{\partial_{x_{S}^{i}} u\left(\bar{x}^{i}\right) / \rho_{S}}{\partial_{x_{0}^{i}} u\left(\bar{x}^{i}\right)}\right)_{V}
$$

The assumption of objective probabilities for the states in date-1, allow the decomposition of agent $i^{\prime} s$ period-1 endowments into a marketed part and a non marketed part, under the $\rho$-inner product. We write

$$
\bar{\omega}^{i}=\bar{\omega}_{M}^{i}+\bar{\omega}_{\perp}^{i}
$$

where $\bar{\omega}_{M}^{i}$ is the marketed part (spanned by the assets) and the non marketed part $\bar{\omega}_{\perp}^{i}, \rho$-orthogonal to the marketed subspace i.e. $\bar{\omega}_{\perp}^{i} \cdot{ }_{\rho} y=0$ for all $y \in\langle V\rangle$. This decomposition is uniquely determined.

We define the aggregate marketed endowment $\bar{w}_{M}=\sum_{i=1}^{I} \bar{\omega}_{M}^{i}$ and the market portfolio $z_{M}$ as the unique portfolio satisfying

$$
V z_{M}=\bar{w}_{M}
$$

For a competitive equilibrium $(\bar{z}, \bar{q})$, we define $\beta_{z}$ for a portfolio $z \in \mathbb{R}^{J}$ by

$$
\beta_{z}=\frac{\operatorname{cov}\left(R_{z}, R_{M}\right)}{\operatorname{var}\left(R_{M}\right)}
$$

where $R_{M}$ is the return of the market portfolio.

We can now state the following results ${ }^{6}$.

\footnotetext{
${ }^{6} \mathrm{Oh}$ (1990) first generalized the GEI-CAPM for non-traded endowments. Herings and Kubler (1999) provide a version of the generalized CAPM based on the Magill-Quinzii (1996) approach. We follow their approach and show that it holds also for endogenous endowments.
} 
Theorem 3 The Generalized CAPM. When var $\left(\bar{w}_{M}\right)>0$, agents maximize mean-variance utility functions with objective probabilities $\rho$, and the riskless bond belongs in the span of the assets, each equilibrium $((\bar{x}, \bar{z}), \bar{q})$ of the economy $\overline{\mathcal{E}}$ has the following properties.

(i) Generalized security market line

The CAPM -pricing formula holds; when $\bar{q} z_{M} \neq 0$, then for each $z \in \mathbb{R}^{J}$,

$$
E\left(R_{z}\right)-\bar{R}=\beta_{z}\left(E\left(R_{M}\right)-\bar{R}\right)
$$

\section{(ii) Generalized fund separation}

Two fund separation holds; for each agent $i$ there exists $\left(a_{1}^{i}, a_{2}^{i}\right) \in \mathbb{R} \times \mathbb{R}_{+}$, where $\sum_{i=1}^{I}\left(a_{1}^{i}\right)=0$ and $\sum_{i=1}^{I}\left(a_{2}^{i}\right)=1$, such that

$$
\bar{x}^{i}-\bar{\omega}_{\perp}^{i}=a_{1}^{i} \mathbf{1}+a_{2}^{i} V z_{M}
$$

\section{(iii) Pricing security}

The ideal security satisfies $\pi_{V}^{*}=a_{1} \mathbf{1}-a_{2} \bar{w}_{M}$, with $a_{1}, a_{2} \gg 0$.

Proof. For a generalized two-fund separation to hold, it is enough to show that the agents' equilibrium consumption bundles exhibit a separation property and they can be written as

$$
\bar{x}^{i}=\bar{\omega}_{\perp}^{i}+a_{1}^{i} \mathbf{1}+a_{2}^{i} \pi_{V}^{*} \text { for some } a_{1}^{i}, a_{2}^{i} \in \mathbb{R}_{+} .
$$

Assume that there exists another consumption bundle $x^{i}$ defined as

$$
x^{i}=\bar{\omega}_{\perp}^{i}+\bar{x}_{\left\langle\mathbf{1}, \pi_{V}^{*}\right\rangle}^{i}
$$

where $\bar{x}_{\left\langle\mathbf{1}, \pi_{V}^{*}\right\rangle}^{i}$ is the $\rho$-orthogonal projection of $\bar{x}^{i}$ onto the subspace spanned by the vectors 1 , and $\pi_{V}^{*}$. It is enough to show that $x^{i}=\bar{x}^{i}$; suppose not and $x^{i} \neq \bar{x}^{i}$. The vector $\bar{x}^{i}-x^{i}$ is then $\rho$-orthogonal to $\bar{\omega}_{\perp}^{i}, \bar{\omega}_{\perp}^{i} \cdot{ }_{\rho}\left(\bar{x}^{i}-x^{i}\right)=0$, since $\pi_{V}^{*} \cdot \rho\left(\bar{x}^{i}-x^{i}\right)=0$ then also $1 \cdot{ }_{\rho}\left(\bar{x}^{i}-x^{i}\right)=0$. It follows that $E\left(\bar{x}^{i}-x^{i}\right)=0$ and $\operatorname{cov}\left(\left(\bar{x}^{i}-x^{i}\right), x^{i}\right)$. Therefore, $E\left(\bar{x}^{i}\right)=E\left(x^{i}\right)$ and $\operatorname{var}\left(\bar{x}^{i}\right)>\operatorname{var}\left(x^{i}\right)$, giving a contradiction to the optimality (remember the assumption of mean variance preferences) of $\bar{x}^{i}$ at prices $\bar{q}$. This is the separation property of equilibrium consumption.

The assumption $\operatorname{var}\left(\bar{w}_{M}\right)>0$ implies that $\bar{w}_{M}$ is not collinear to $\mathbf{1}$ (zero variance) and it holds that $\pi_{V}^{*}=c^{\prime} \mathbf{1}-c \bar{w}_{M}$ for some numbers $c$ and $c^{\prime}$, i.e. the 
ideal security always belong to the span $\left\langle\mathbf{1}, \bar{w}_{M}\right\rangle$. The separation property implies that $\bar{w}_{M} \in\left\langle\mathbf{1}, \pi_{V}^{*}\right\rangle$ since in equilibrium $\bar{w}_{M}=\sum_{i=1}^{I}\left(\bar{x}^{i}-\bar{\omega}_{\perp}^{i}\right)$. The generalized two fund separation follows immediately $\bar{x}^{i}-\omega_{\perp}^{i}=a_{1} \mathbf{1}+a_{2} V z_{M}$ for some numbers $a_{1}^{i}, a_{2}^{i}$. Since $w_{M}=\sum_{i=1}^{I} a_{1} \mathbf{1}+\sum_{i=1}^{I} a_{2} V z_{M}$ and $\operatorname{var}\left(\bar{w}_{M}\right)>$ 0 , we have $\sum_{i=1}^{I}\left(a_{1}^{i}\right)=0$ and $\sum_{i=1}^{I}\left(a_{2}^{i}\right)=1$.

To prove that the constants $c$ and $c^{\prime}$ are strictly positive, we proceed as follows. Since $\bar{w}_{M} \in\left\langle\mathbf{1}, \pi_{V}^{*}\right\rangle$, its cost is given by $\overline{q w}_{M}=\left(E\left(\bar{w}_{M}\right) /(1+\bar{r})\right)+$ $\operatorname{cov}\left(\pi_{V}^{*}, \bar{w}_{M}\right)$ and because of $\operatorname{cov}\left(\pi_{V}^{*}, \bar{w}_{M}\right)=-\operatorname{cvar}\left(\bar{w}_{M}\right)$, we get $\overline{q w}_{M}=$ $\left(E\left(\bar{w}_{M}\right) /(1+\bar{r})\right)-\operatorname{cvar}\left(\bar{w}_{M}\right)$. By assumption $\operatorname{var}\left(\bar{w}_{M}\right)>0$ and if $c<0$, there exists some agent for whom $\operatorname{var}\left(\bar{x}^{i}\right)$ and $\overline{q x}^{i}>E\left(\bar{x}^{i}\right) /(1+\bar{r})$. But in this case the consumption bundle $\widetilde{x}^{i}=\left(\bar{x}_{o}^{i}, E\left(\bar{x}^{i}\right) \mathbf{1}\right)$ is strictly preferred to $\bar{x}^{i}$ since it is less expensive, belongs into $\langle V\rangle$ and satisfies the budget contstraints. But this is a contradiction and so $c>0$. Moreover, the cost of the riskless asset is positive and given by $\bar{q} \mathbf{1}=E \pi_{V}^{*}=c^{\prime}-c E\left(\bar{w}_{M}\right)>0$. Therefore $c^{\prime}>0$ since $E\left(\bar{w}_{M}\right)>0$.

The CAPM pricing formula (or the generalized security market line) is obtained by substituting in the $(3) z_{V}^{*}=c^{\prime} \mathbf{1}-c z_{M}$. We have

$$
\frac{\operatorname{cov}\left(R_{z}, R_{z^{*}}\right)}{\operatorname{var}\left(R_{z^{*}}\right)}=-\frac{\bar{q} z}{c \bar{q} z_{M}} \frac{\operatorname{cov}\left(R_{z}, R_{M}\right)}{\operatorname{var}\left(R_{M}\right)}
$$

and

$$
E\left(R_{z^{*}}\right)-\bar{R}=\frac{c^{\prime}-c E\left(V z_{M}\right)}{\bar{q} z^{*}}-\bar{R}
$$

it follows that

$$
E\left(R_{z^{*}}\right)-\bar{R}=\beta_{z}\left(E\left(R_{z_{M}}\right)-\bar{R}\right),
$$

which is nothing else but the well known beta pricing formula.

The version of the two-fund separation considered in the theorem is more general than the usual one in the sense that it contains as special cases both the cases of marketed and non tradable endowments.

In standard versions of GEI-CAPM (Geanakoplos and Shubik (1990), Magill and Quinzii (1996)), a crucial assumption is that the initial income stream of each agent is exogenous and marketed. Our generalized two fund separation delivers the version

$$
\bar{x}^{i}=a_{1}^{i} \mathbf{1}+a_{2}^{i} w
$$


since $\bar{\omega}_{\perp}^{i}=0$ for every $i$.

Our result accounts also for versions of the two-fund separation that holds for cases where endowments are non marketed but exogenously given (Oh (1996), Willen (1997)). In this case the final income stream consumed by each agent consists not only of the returns of a linear combination of the riskless bond and the market portfolio, but also of the undiversifiable nonmarketed individual part of the initial stream $\bar{\omega}_{\perp}^{i}$. This result is sometimes called "three-fund separation". The difference between our model and the one with exogenous non-traded endowments stands to the fact that both the marketed and the undiversifiable individual part is endogenous.

\section{Financial Innovation}

In this section, we examine the effects of financial innovation in our CAPM with quadratic utilities. We prove that in the presence of endogenous undiversifiable returns and when the asset structure changes, the relative price of any two assets may change contradicting in this way the standard price invariance result due to the quadratic preferences assumption.

We, first state our financial innovation proposition for quadratic utilities and then apply it in the linear quadratic case, assume a less general functional form for the stochastic transfer technology, we prove existence of equilibrium and give an example of a GEI-CAPM with endogenous endowments. With non tradable endogenous endowments equilibrium is not pareto optimal as in the case of endowments spanned by the assets and in addition, markets are not stable in the sense that completing the market by adding a new asset does not necessarily make everybody better off. Asset prices remaining the same means that the introduction of the new asset had no real effect on output (aggregate endowment), this is because the undiversifiable component of the aggregate endowment varies with the market structure. Introducing or withdrawing an asset in the market span may improve as well as worsen the economy in terms of pareto efficiency.

Up to now the findings of the GEI-CAPM literature concerning the portfolio formation carries out also in our framework of transferable endowments. Oh (1990) finds that in the CAPM with quadratic utilities relative prices of assets remain the same as the market structure changes. He generalizes Rubinstein's "resource distribution irrelevancy" where initial endowments were 
marketed.

In this section we will add two assumptions.

Quadratic Utilities $v^{i}\left(x^{i}\right)=x^{i}-\frac{\alpha^{i}}{2}\left(x^{i}\right)^{2}$ all $i=1, \ldots, I$ in both first and second periods.

Monotonicity $1-\alpha^{i} \bar{w}_{0} \gg 0$ and $\mathbf{1}-\alpha^{i} \bar{w}_{1} \gg 0$ for all $i=1, \ldots, I$.

An individual's first order conditions for security demands, evaluated at the competitive equilibrium, is ${ }^{7}$

$$
\bar{q}\left(1-\alpha^{i} x_{0}^{i}\right)=\left(1-\alpha^{i}\left(\omega_{1}^{i}+\sum_{i=1}^{I} V^{j} z_{j}^{i}\right)\right)(\rho \square V) .
$$

After rearranging these expressions, summing over individuals, using the market clearing conditions $\sum_{i=1}^{I} z_{j}^{i}=0$, all $j=1, \ldots, J$, we obtain

$$
\bar{q}=\mu_{1}\left(\mu_{2} \mathbf{1}-\left(\bar{w}_{1}\right)\right)(\rho \square V) .
$$

where $\mu_{1}=1 /\left(\sum_{i=1}^{I} \frac{1}{\alpha^{i}}-\sum_{i=1}^{I} x_{0}^{i}\right), \mu_{2}=\sum_{i=1}^{I} \frac{1}{\alpha^{2}}$.

Proposition 4 Financial Innovation. In a GEI-CAPM economy with quadratic utilities and endogenous endowments the relative prices of the marketed securities depend on the financial structure.

Proof. From (7) we have that $\overline{q_{j}}=\mu_{1}\left(\mu_{2} \mathbf{1}-\left(\bar{w}_{\mathbf{1}}\right)\right)\left(\rho \square V^{j}\right)$ for $j=$ $1, \ldots, J$. The relative prices

$$
\frac{\overline{q_{j}}}{\overline{q_{j^{\prime}}}}=\frac{\left(\mu_{2} \mathbf{1}-\left(\bar{w}_{1}^{V}\right)\right)\left(\rho \square V^{j}\right)}{\left(\mu_{2} \mathbf{1}-\left(\bar{w}_{\mathbf{1}}^{V}\right)\right)\left(\rho \square V^{j^{\prime}}\right)}
$$

of the assets since they depend on the aggregate output $\bar{w}_{\mathbf{1}}$ which in turn depends on the financial structure represented by the matrix $V$.

Corollary 5 Price Invariance. The prices of assets which belong to the initial asset structure $V$ are invariant to its modification to $V^{\prime}$ if and only if

$$
\left(\left(\bar{w}_{\mathbf{1}}^{V}\right)-\left(\bar{w}_{\mathbf{1}}^{V^{\prime}}\right)\right)(\rho \square V)=0,
$$

in other words, the modification of the financial structure does not change the marketed subspace or the market is complete (or effectively complete) under $V$.

\footnotetext{
${ }^{7}$ We introduce the box-product $\square$ such as for $x, y \in \mathbb{R}^{S}, x \square y=\left(x_{1} y_{1}, \ldots, x_{S} y_{S}\right)$.
} 


\subsection{The case of linear-quadratic preferences}

Consider now that each agent's utility function is defined by

$$
u^{i}\left(x^{i}\right)=\gamma_{0}^{i} x_{0}^{i}+\delta^{i} E\left(x_{\mathbf{1}}^{i}-\frac{\alpha^{i}}{2}\left(x_{\mathbf{1}}^{i}\right)^{2}\right), i=1, \ldots, I,
$$

with $\gamma_{0}^{i}>0$, all $i$ and the monotonicity conditions hold for second period's quadratic utility functions.

Obviously, the generalized CAPM theorem applies in the linear quadratic case since the latter constitutes a special case of mean variance preferences. Its specification with endogenous endowments delivers an easy computable equilibrium. In the rest of this section, we prove existence of equilibrium, we summarize the application of the Financial Innovation proposition in a lemma, assume a special functional form for the stochastic transfer technologies and solve a numerical example, given this specification.

Proposition 6 Existence. Under the assumption of linear quadratic utilities and the requirement that $\widetilde{\lambda}^{i}(0)=\omega_{s}^{i}, s=1, \ldots, S$, there exists a pair of actions and prices $\left(\left(x^{i}, l^{i}, z^{i}\right), \bar{q}\right) \in \mathbb{R}_{+}^{(S+1) I} \times \mathbb{R}^{I} \times \mathbb{R}^{J I} \times \mathbb{R}^{J}$ that satisfies the definition of an equilibrium for the GEI-CAPM economy with endogenous endowments $\overline{\mathcal{E}}\left(u, \omega_{0}, V, \widetilde{\lambda}\right)$.

Proof. The requirement of a non trivial equilibrium that $0<l^{i}<\omega_{0}^{i}$, for at least one $i, i=1, \ldots, I$ and the additional assumption on the transfer technology $\widetilde{\lambda}^{i}(0)=\omega_{s}^{i}, s=1, \ldots, S$, where $\omega^{i} \in \mathbb{R}^{S}$, guarantee the validity of the boundary condition $1 \leq \bar{\omega}_{s}^{i}\left(l^{i}\right) \leq \Lambda$, with $1 \leq \Lambda \leq \infty$. Hence ${ }^{8}$, we can construct the following existence argument.

We define the equilibrium map $\varphi: \prod_{1=1}^{I}\left[0, \omega_{o}^{i}\right] \rightarrow \prod_{1=1}^{I}\left[0, \omega_{o}^{i}\right]$ which maps any vector $\beta \in \mathbb{R}^{I}$ to a vector $\left(l^{i}\left(q^{*}(\beta)\right)_{i=1}^{I}\right.$.

For a given $\beta \equiv\left(l^{i}\right)_{i=1}^{I}$, our model is a standard GEI with exogenous endowments for which we know that equilibrium exists and it is unique ${ }^{9}$. The corresponding equilibrium prices are $q^{*}(\beta)$, the corresponding transfers $l^{i}\left(q^{*}(\beta)\right)$. Hence, the map $\varphi$ is well defined.

\footnotetext{
${ }^{8}$ See Appendix I, for a proof of the necessity of the boundary condition.

${ }^{9}$ The quasi linearity of the utility function quarantees uniqueness of equilibrium in the standard finance GEI model. Assuming interior solutions in the latter we can construct our existence argument.
} 
Moreover $\varphi$ is continuous with respect to $\beta$ and maps $\prod_{1=1}^{I}\left[0, e_{o}^{i}\right]$ to itself. Then by Brouwer's fixed point theorem $\varphi$ has a fixed point, i.e. $\exists \beta^{*}$ such that $\beta^{*}=l\left(q^{*}\left(\beta^{*}\right)\right)$.

But $\beta^{*}$ corresponds exactly to a GEI for our model.

\section{An example}

We illustrate our findings in terms of an example with two agents with linear quadratic utilities and the assumption that after transfer endowments are given by the vector $\bar{\omega}^{i}=\left(\bar{\omega}_{0}^{i}, \bar{\omega}_{\mathbf{1}}^{i}\right)=\left(\omega_{0}^{i}-l^{i}, \bar{\omega}_{\mathbf{1}}^{i}\right) \in \mathbb{R}_{+}^{S+1}$ where $\bar{\omega}_{\mathbf{1}}^{i}=\omega_{\mathbf{1}}^{i} \square$ $\left(\mathbf{1}+\lambda_{\mathbf{1}}^{i}\right), \mathbf{1}=(1, \ldots, 1) \in \mathbb{R}^{S}$ and $\lambda_{\mathbf{1}}^{i}$ the vector of output realizations. ${ }^{10}$

Allowing for the transfer of endowments does not necessarily account for the failure of the invariance of asset prices across market structures. For instance, for the class of non stochastic linear transfer technologies and certain second period endowments, the equilibrium prices depend only on parameters which are given independently of the market structure and accordingly are invariant with respect to financial innovation.

The substitution of a concave transfer technology for a linear transfer process in the above illustration changes dramatically the results and the price variance obtains. In a two periods economy where agent can transfer endowments via the linear technology $\lambda^{1}\left(l^{1}\right)=1+l^{1}$ while agent two via the $\lambda^{2}\left(l^{2}\right)=1+(1 / 2) \sqrt{l^{2}}$, a change in the return structure from $V=\left[\varepsilon_{1}\right]$ to $V^{\prime}=\left[\varepsilon_{1}, \varepsilon_{2}\right]$, where $\varepsilon_{i}$ is the zero vector with 1 as its $i^{\text {th }}$ coordinate (i.e. from one Arrow security to two Arrow securities structure), modifies the equilibrium price of asset 1 under the market structure $V, \bar{q}_{1 \mid V}$, to $\bar{q}_{1 \mid V^{\prime}} \neq \bar{q}_{1 \mid V}$ when the asset structure is $V^{\prime}$. The system of equations which characterizes the competitive equilibrium prices and allocations is

$$
\begin{aligned}
& q_{1}=\rho_{1}\left(1-\alpha^{1}\left(z_{1}^{1}+\omega_{2}^{1}\left(1+l^{1}\right)\right)\right) \\
& 1=\omega_{2}^{1}\left(1-\alpha^{1}\left(\omega_{2}^{1}\left(1+l^{1}\right)+\rho_{1} z_{1}^{1}+\rho_{2} z_{2}^{1}\right)\right) \\
& q_{1}=\rho_{1}\left(1-\alpha^{2}\left(z_{1}^{2}+\omega_{2}^{2}\left(1+(1 / 2) \sqrt{l^{2}}\right)\right)\right) \\
& 1=\omega_{2}^{2}\left(1 / \sqrt{l^{2}}\left(1-\alpha^{2}\left(\omega_{2}^{2}\left(1+(1 / 2) \sqrt{l^{2}}\right)+\rho_{1} z_{1}^{2}+\rho_{2} z_{2}^{2}\right)\right)\right. \\
& 0=z_{1}^{1}+z_{1}^{2} \\
& 0=z_{2}^{1}+z_{2}^{2} \\
& q_{2}=\rho_{2}\left(1-\alpha^{1}\left(z_{2}^{1}+\omega_{2}^{1}\left(1+l^{1}\right)\right)\right)
\end{aligned}
$$

\footnotetext{
${ }^{10}$ Not to be confused with the transfer function notation.
} 


$$
q_{2}=\rho_{2}\left(1-\alpha^{2}\left(z_{2}^{2}+\omega_{2}^{2}\left(1+(1 / 2) \sqrt{l^{2}}\right)\right)\right) .
$$

The last three equations in this system correspond respectively to the market clearing condition for the second asset and the first order conditions with respect to the second Arrow security of individuals one and two. Solving the system with $z_{2}^{1}=z_{2}^{2}=0$ and ignoring the last three equations yields competitive equilibrium prices and allocations for the economy with asset structure $V$. After computing the resulting equilibrium prices for both asset structures we derive the following condition:

Equilibrium prices $\bar{q}_{1 \mid V^{\prime}}$ and $\bar{q}_{1 \mid V}$ will coincide if and only if $2 \omega_{2}^{1}(1-$ $\left.\alpha^{2} \omega_{2}^{2}\right)=2+\alpha^{2}\left(\omega_{2}^{2}\right)^{2}$ is satisfied.

Therefore, whatever the considered economy, there may be a unique value of $\bar{e}_{2}^{1}$ for which price invariance obtains; otherwise, the equilibrium price of asset $1 \bar{q}_{1}$ varies almost always with financial innovation.

\section{Conclusions}

In this work we have shown that the two basic results of the CAPM when agents are given the ability to influence future non-traded income in the framework of incomplete markets are still valid. The two-funds separation theorem and the security market line can still serve as prediction of the portfolio composition of the agents and of the way assets are priced at equilibrium. The new aspect that appears in this framework is the possibility of theoretical discussions concerning financial innovation. Our model can be seen as a generalization of the GEI-CAPM with quadratic utilities (Oh (1996), Willen (1997)), since it generates a result that includes as special cases previous predictions, asset prices may change when the financial market changes. We believe that this finding should be further explored and may give valuable intuition about the reasons of asset prices variability. In the framework we develop in this paper is that, when endowment transfers are allowed, the informational requirements (among the other assumptions that imply the basic theorem) become extremely stringent. They involve not only the observation of all individual endowments but also of each agent's transfer process. But this is a more general problem in theory which has been always justified by the fact that "all strong assumptions lead to clear cut results with strong intuitive appeal" (Magill and Quinzii (1996)).

Our proposition on financial innovation may deserve more attention in future work as it may serve as a starting point in the study and understanding 
of some well known problems in the literature of financial macroeconomics, for instance the equity premium puzzle or the risk free puzzle. The CAPM has been extensively used in the financial literature due to its powerful predictions and its intuitive appeal. One of the major drawbacks of the CAPM with quadratic utilities is that it involves increasing absolute risk aversion which imply that risky assets are inferior goods (Arrow (1970)). Introducing undiversifiable productive returns may modify the investors marginal rates of substitution through the type of correlation between the marginal rates of transformation, induced by the technologies, and the returns on the traded assets. 


\section{Appendix}

At a first sight, existence of equilibrium might be a problem. The reason is that $\lambda_{s}^{h}\left(l^{h}(q)\right)$ through its dependence on $l^{h}(q)$ makes endowments price dependent. The problem is that, with price dependent endowments, the boundary behavior of demand $\left(\lim c_{p \rightarrow \infty}=0\right.$, $\left.\lim c_{p \rightarrow 0}=\infty\right)$, no longer suffices to use traditional equilibrium proves. As an illustration we can consider the following example: an exchange economy with two individuals $h=1,2$ (superscripts) and two goods $i=1,2$, (subscripts) we normalize the price of good one to 1 and we assume the endowment of $h=1$ for good 2 price dependent. Individuals maximize utilities

$$
\begin{aligned}
& \max c_{1}^{1} \text { s.to } c_{1}^{1}+p c_{2}^{1} \leq \omega_{1}^{1}+p \omega_{2}^{1}(p), \\
& \max c_{2}^{2} \text { s.to } c_{1}^{2}+p c_{2}^{2} \leq \omega_{1}^{2}+p \omega_{2}^{2},
\end{aligned}
$$

equilibrium prices will be such that

$$
\begin{aligned}
c_{1}^{* 1}+c_{1}^{* 2} & =\omega_{1}^{\text {aggr }}, \\
c_{1}^{* 1} & =\omega_{1}^{1}+\omega_{1}^{2}=\omega_{1}^{1}+p \omega_{2}^{1}(p) \\
& \Leftrightarrow p \omega_{2}^{1}(p)=\omega_{1}^{2},
\end{aligned}
$$

existence fails if $\omega_{2}^{1}(p)=\frac{u}{p}$, any $u>0$ and $u \neq \omega_{1}^{2}$. The problem can be discarded only if we require $\omega_{2}^{1}(p)$ to be bounded. When $0<\underline{\omega} \leq \omega_{2}^{1}(p) \leq$ $\bar{\omega} \leq \infty$, the excess demand function $f(p)=p \omega_{2}^{1}(p)$ is again surjective and equilibrium exists. 


\section{References}

[1] Breeden, D., (1979), "An Intertemporal Asset Pricing Model with Stochastic Consumption and Investment Opportunities," Journal of Financial Economics, Vol. 7, 265-296.

[2] Geanakoplos J. and M. Shubik, (1990), "The Capital Asset Pricing Model as a General Equilibrium with Incomplete Asset Markets," The Geneva Papers on Risk and Insurance Theory, Vol. 15, 55-71.

[3] Grossman, S. and R. Shiller, (1982), "Consumption Correlatedness and Risk Measurement in Economics with Non-traded Assets and Heterogeneous Information," Journal of Financial Economics, Vol. 10, 195-210.

[4] Herings J. J. and F. Kubler (1999), "The robustness of the CAPM-A Computational Approach" CentER Discussion Paper,No. 9954, CentER, Tilburg University.

[5] Lintner J., (1965), "The Valuation of Risky Assets and the Selection of Risky Investments in Stock Portfolios and Capital Budgets," Review of Economics and Statistics, Vol. 47, 13-37.

[6] Magill M. and M. Quinzii, (1996), Theory of Incomplete Markets, Vol. 1, The MIT Press, Cambridge, Massachusetts.

[7] Mayers D., (1972), "Non-Marketable Assets and Capital Market Equilibrium under Uncertainty," in M. Jensen (eds), Studies in the Theory of Capital Markets, New York: Praeger, 79-121.

[8] Markowitz, H. M., (1959), "Portfolio Selection: Efficient Diversification of Investment,", Yale University Press, New Haven.

[9] Mossin J., (1966), "Equilibrium in a Capital Asset Market," Econometrica, Vol. 34, No. 4, 768-773.

[10] Oh G., (1996), "Some Results in the CAPM with Nontraded Endowments," Management Science, Vol. 42, 286-293.

[11] Rubinstein, M. (1974), "An Aggregation Theorem for Securities Markets", Journal of Financial Economics, Vol. 46, 605-615. 
[12] Sharpe W., (1964), "Capital Asset Prices: A Theory of Market Equilibrium under Conditions of Risk," Journal of Finance, Vol. 19, No.3 425-442.

[13] Willen P., (1997), "A Model which Allows for Comparison of Different Levels of Market Incompleteness",mimeo, Yale University, New Haven. 